\title{
Globe
}

Revue internationale d'études québécoises

Joseph Yvon Thériault : Critique de l'américanité. Mémoire et démocratie au Québec. Montréal, Québec Amérique, 2002 Donald Cuccioletta, Jean François Côté et Frédéric Lesemann (dir.) : Le grand récit des Amériques. Québec, Presses de l’Université Laval, 2001

Donald Cuccioletta (dir.) : L'américanité et les Amériques. Québec, Presses de l’Université Laval, 2001

\section{Maureen Waters}

Volume 6, numéro 1, 2003

URI : https://id.erudit.org/iderudit/1000702ar

DOI : https://doi.org/10.7202/1000702ar

Aller au sommaire du numéro

Éditeur(s)

Globe, Revue internationale d'études québécoises

ISSN

1481-5869 (imprimé)

1923-8231 (numérique)

Découvrir la revue

Citer ce compte rendu

Waters, M. (2003). Compte rendu de [Joseph Yvon Thériault : Critique de l'américanité. Mémoire et démocratie au Québec. Montréal, Québec Amérique, 2002 / Donald Cuccioletta, Jean François Côté et Frédéric Lesemann (dir.) : Le grand récit des Amériques. Québec, Presses de l’Université Laval, 2001 / Donald Cuccioletta (dir.) : L'américanité et les Amériques. Québec, Presses de l'Université Laval, 2001]. Globe, 6(1), 182-186. https://doi.org/10.7202/1000702ar d'utilisation que vous pouvez consulter en ligne. 
L'intérêt premier de cette collection de textes ne relève pas foncièrement du logos, ni même du pathos lyrique auquel l'auteur ne se refuse guère ("Le réel a pris l'aspect du rictus de Dieu ", "Âge de fer ", p. 49), mais plutôt d'une qualité qui - Chamberland nous aide à le comprendre - se fait rarissime : le refus du cynisme.

Maxime Prévost McMaster University

\section{Joseph Yvon Thériault}

Critique de l'américanité.

Mémoire et démocratie au Québec

Montréal, Québec Amérique, 2002.

\section{Donald Cuccioletta, Jean François Côté et Frédéric Lesemann (dir.)}

Le grand récit des Amériques

Québec, Presses de l'Université Laval, 2001.

\section{Donald Cuccioletta (dir.)}

\section{L'américanité et les Amériques}

Québec, Presses de l'Université Laval, 2001.

Au cours des dernières décennies, de nombreux ouvrages consacrés à l'américanité sont parus au Québec. Parmi les plus récents, notons celui de Joseph Yvon Thériault, Critique de l'américanité : mémoire et démocratie au Québec, dans lequel nous trouvons une des premières tentatives visant à commenter l'ensemble de cette production. L'auteur souligne, dans un premier temps, la contradiction inhérente au discours gravitant autour de l'américanité; en effet, elle semble devoir être présentée à la fois comme une pensée forte, en raison du réalignement tant politique que culturel du Québec vers les États-Unis qu'elle semble impliquer, et comme une pensée molle en raison de son caractère d'évidence. Thériault développe l'idée de l'américanité comme pensée forte, révélatrice d'une impasse dans le cheminement identitaire de la 
nation française d'Amérique. Il perçoit d'ailleurs cette nouvelle mode pour l'américanité comme a une manière excessive d'exprimer ici un malaise propre à la modernité radicale et sa négation des dimensions subjectives de la vie sociale. (p. 15). Son travail consiste à déconstruire l'américanité, version québécoise, pour démontrer ses insuffisances ainsi que les limites de la conception de la modernité sur laquelle elle s'appuie. Or, l'auteur affirme que son livre - "rédigé comme un pamphlet du type "pour en finir avec l'américanité" - (p. 15) - serait né d'un projet visant à écrire une histoire intellectuelle de la démocratie et du nationalisme. Cela explique pourquoi son corpus ne concerne pas la société québécoise comme telle, mais plutôt la représentation de cette société à travers la production intellectuelle contemporaine. Selon Thériault, l'américanité québécoise est en contradiction avec le sentiment national, puisqu'elle évacue la dimension substantielle de l'histoire de la nation française d'Amérique afin de réduire l'histoire du Québec "aux procès d'institutionnalisation de la société moderne " (p. 173).

L'auteur se défend contre d'éventuelles critiques en reconnaissant que l'on pourrait lui reprocher d'être trop négatif envers ses contemporains. Notons par exemple qu'au sujet de Gérard Bouchard a qui s'impose comme le maitre à penser de l'américanité et de la nouvelle histoire québécoises " (p. 146), Thériault suggère que : "sa grande sensibilité à la réalité québécoise le force à introduire dans ses analyses des éléments de la vie sociale que son modèle ne laissait nullement deviner, sinon rejetait carrément" (p. 147). S'il reconnaît une certaine valeur à la démarche comparatiste de Bouchard, Thériault se demande par ailleurs pourquoi "les sociétés neuves se distingueraient [...] de[s] vieilles sociétés si, dans les unes comme dans les autres, selon leur parcours chaque fois particulier, tout est possible - (p. 156). Bref, la thèse de Bouchard "met en pleine lumière tout ce que l'américanité ne saurait penser - (p. 147) et se transforme en thèse molle pour Thériault. Il consacre également des parties de son étude aux contributions de Jocelyn Létourneau, de Jean Morency, d'Yvan Lamonde et de Fernand Dumont, et cette liste d'auteurs est loin d'être exhaustive.

Même si son ouvrage s'annonce comme un projet déconstructionniste, Thériault présente dans la dernière section de son livre quelques éléments préliminaires à ce qui serait aujourd'hui, selon lui, a une attitude intellectuelle positive et reconstructive o à l'égard de la question du Québec (p. 266). Il propose alors dans les deux derniers chapitres de 
démontrer quelles sont les traces de la tradition canadienne-française au Québec.

Tout lecteur, quelle que soit sa position au sujet de la notion d'américanité, ne peut manquer d'apprécier le fait que Thériault souligne les failles les plus importantes dans le discours québécois autour de cette notion. Soulignons à ce sujet le souci qui est le sien de revenir sur la terminologie de base. L'auteur nous rappelle que l'américanité n'est pas l'américanisation et que cette formule "sert d'avance de réponse à ceux ou celles qui voudraient voir dans l'américanité québécoise un consentement au modèle états-unien, à ses valeurs, à sa culture, à ses formes de sociabilité, à ses politiques sociales ou à son impérialisme " (p. 71). Thériault essaie de démontrer l'inconséquence de la plupart des références québécoises à l'américanité qui confondent américanité, modernité et modernisation :

Les Américains n'ont inventé ni la machine à vapeur, ni le chemin de fer, ni le cinéma, ni le télégraphe, ni le téléphone, ni encore la pizza au four à bois ou le lait Nestlé. Dans la plupart des sociétés occidentales ayant traversé un tel processus, on nomme cela plus simplement la modernisation, non pas l'américanisation et encore moins l'américanité. (p. 79)

L'auteur attribue une partie de la confusion au fait que "l'avancée de la modernisation technique du Québec s'est déroulée en même temps que la continentalisation et l'américanisation de son économie * (p. 79). Dans la même veine, Thériault nous invite à réfléchir au fait que pour parler de l'identité québécoise d'avant la Révolution tranquille, le terme de "Canadiens français " soit souvent remplacé par celui de "Québécois ": "Une telle substitution est une faute historique, elle n'a de sens que si l'on parle de l'espace sociétal du Québec et non de l'identité des groupes qui y habitaient • (p. 19), s'exclame Thériault à juste titre.

Chaque lecteur de Thériault devrait, cependant, se garder de tirer une vision trop réductrice de la question de l'américanité. Rappelons qu'il aborde uniquement l'américanité québécoise, qu'il n'examine pas les rapports entre l'américanité et son cousin l'americanidad, par exemple, et que son étude ne se consacre pas de manière égale à l'américanité québécoise telle qu'elle se définit chez les sociologues, les historiens, les écrivains et les autres. Une véritable curiosité intellectuelle 
nourrie par le vaste sujet qu'est l'américanité nous oblige à approfondir notre point de vue à l'aide de perspectives diverses et multiples. Ainsi, pour ceux qui, justement, désirent se familiariser avec une pluralité de voix américaines, nous pouvons recommander deux autres parutions récentes. Réunis autour du Groupe interdisciplinaire de recherche sur les Amériques (GIRA), des chercheurs du Mexique, des États-Unis et du Québec analysent la question de l'américanité dans le cadre d'une démarche comparatiste et continentale dans Le grand récit des Amériques. Dès l'introduction, cet ouvrage souligne le fait incontestable que " la rencontre, récente ou "initiale", de l'autre (migrant ou autochtone) est au cœur du processus identitaire et, dans ce sens, le questionnement sur la transculturation met en scène un processus remontant aux origines mêmes de l'aventure en Amérique • (p. 3). La diversité des contributions de Jean-François Côté, Donald Cuccioletta, Annick Germain, Isidro Morales, Patrick Imbert, Robert L. Schwartzwald, Deborah Altamirano, Daniel Mato, Nicolas van Schendel, Ricardo Ortiz et Gérard Bouchard est au cœur de la spécificité et de la force de cet ouvrage qui aborde véritablement, comme l'indique son sous-titre, la notion de la "polyphonie des identités culturelles dans le contexte de la continentalisation .

L'américanité et les Amériques présente également une collection d'essais particulièrement intéressants qui tentent de traverser l'ensemble des questions, des mythes, voire des mensonges, qui traversent les débats sur l'américanité. Retenons surtout l'excellente définition suivante, tirée de l'introduction et pouvant servir de cadre à toute étude portant sur l'américanité :

Le concept de l'américanité renvoie, de fait, à une dimension à la fois distinctive et commune de l'ensemble des peuples, des groupes culturels et même des individus qui habitent le continent des Amériques. Ce n'est pas une identité exclusive, comme certains l'entendent, d'un peuple ou d'un groupe culturel en particulier. Il revient à chacun de découvrir les éléments de son appartenance américaine. Si nous, dans l'hémisphère nord, parlons d'américanité (des Québécois, des Canadiens et des États-Uniens), dans le sud, plus particulièrement en Amérique latine, on invoque le concept de l'Americanidad. Ainsi, la source commune à tous de l'américanité, c'est le continent (hémisphères nord et sud) et le rapport culturel et identitaire avec ce continent (p. 2). 


\section{REVUE INTERNATIONALE D'ÉTUDES QUÉBÉCOISES}

Étant donné que l'américanité s'avère être à la fois un sujet controversé et complexe, l'approche comparative, telle que la lecture conjointe de ces trois ouvrages le permet, nous semble permettre d'apprécier la diversité des opinions à une échelle pan-américaine.

Maureen Waters

Université Paris III, Sorbonne Nouvelle 